\title{
White Piedra. Experience with 12 cases
}

Alexandro Bonifaz, Javier Araiza, Alejandra Rodríguez-Leviz, Daniela Guzmán, Selene Gutierrez Dermatology Service. Hospital General de México. Dr. Eduardo Liceaga

\section{Introduction.-}

- White piedra (WP) is a superficial mycosis caused by yeast fungi of the genera Trichosporon, is a rare infection and asymptomatic, affects the hair at the level of the stem in the form of concretions or adherent nodules. The main etiological agents are: Trichosporon inkin, Trichosporon ovoides, Trichosporon cutaneum

\section{Objective.-}

- Is to present our clinical-mycological and therapeutic experience of twelve cases

\section{Material \& Methods.-}

- A retrospective study of WP, seen in the Dermatology Service from 2005 to 2017 (twelve years), was carried out. All cases underwent a clinical history and the diagnosis was checked by the following tests: with Wood's light. Hair was taken for direct tests with $\mathrm{KOH}$ (10\%); $\mathrm{KOH}+$ cotton blue and some parasitized hairs were performed scanning electron microscopy (Jeol ${ }^{\circledR}$ microscope, model JSM-5300); cultures in Sabouraud dextrose agar media with and without antibiotics. The cultures were confirmed by micromorphology and confirmed by two methods: assimilation of carbohydrates by commercial system VITEK ${ }^{\circledR}$ 2YST IDcard and by protein identification with MALDI-TOF MS system (Vitek-MS ${ }^{\circledR}$ ). The treatment was based on ketoconazole $(2 \%)$ in shampoo for $1-2$ months and the cases of failure were used Hoffman's liquor (alcohol / ether) $+1 \%$ salicylic acid, or one of them plus oral itraconazole.
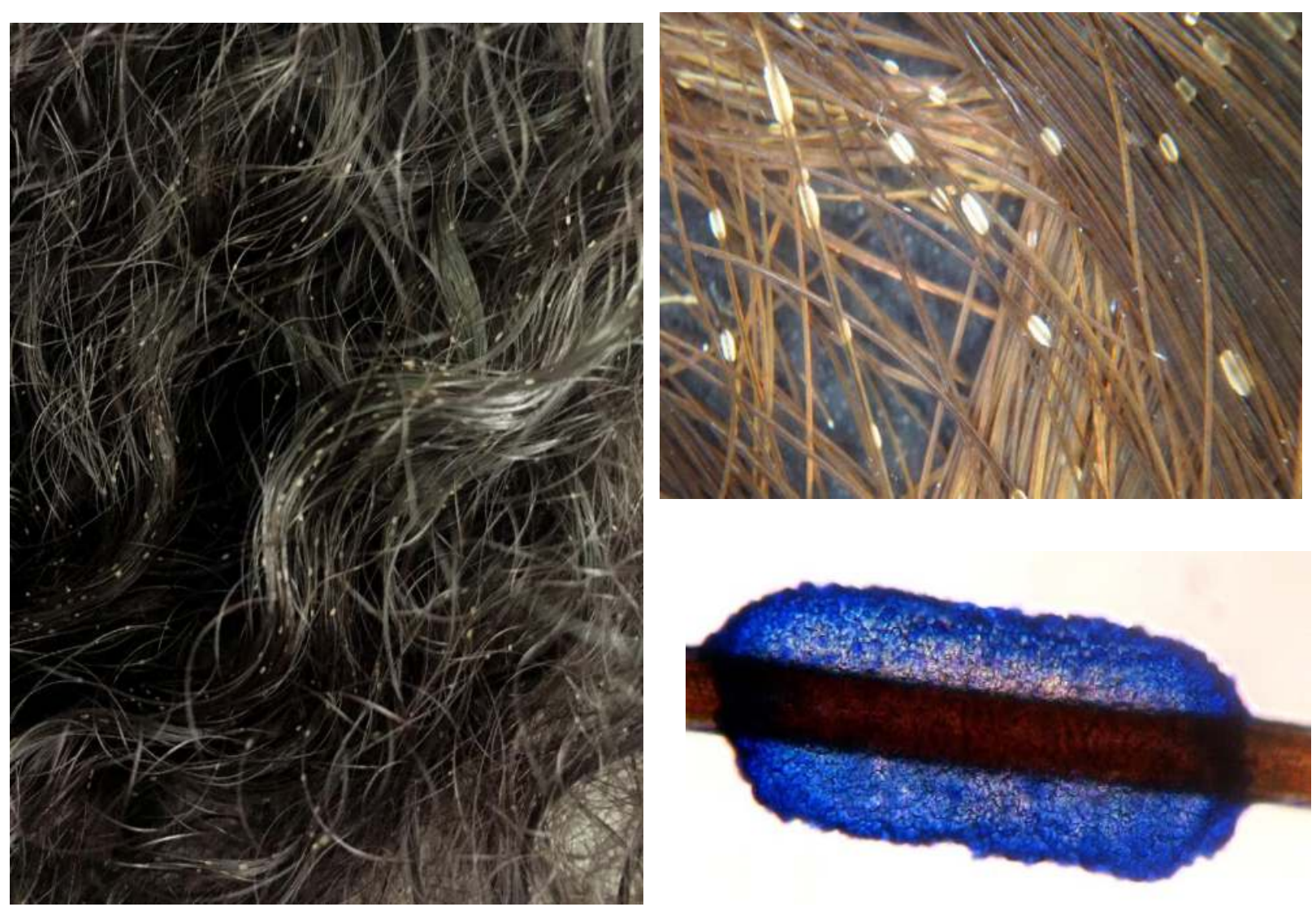

- Treatment response: Ketoconazole shampoo (2\%): 09/12 cases (75.0\%); Itraconazole ( $200 \mathrm{mg} /$ day) + ketoconazole shampoo (2\%) 1/12 (8.4\%) and Hoffman liqueur plus salicylic acid 2/12 (16.6\%).

\section{Conclusion.-}

- The WP, is a rare fungal infection, which affects more the head hairs, our main etiological agent was Trichosporon inkin (83\%). The majority of cases were in school-age girls. All the cases presented hairs concretions with conidia. In $75 \%$ of cases clinical and mycological cure was achieved with ketoconazole shampoo.
Table 1. Demographic, clinical, mycological and therapeutic data.

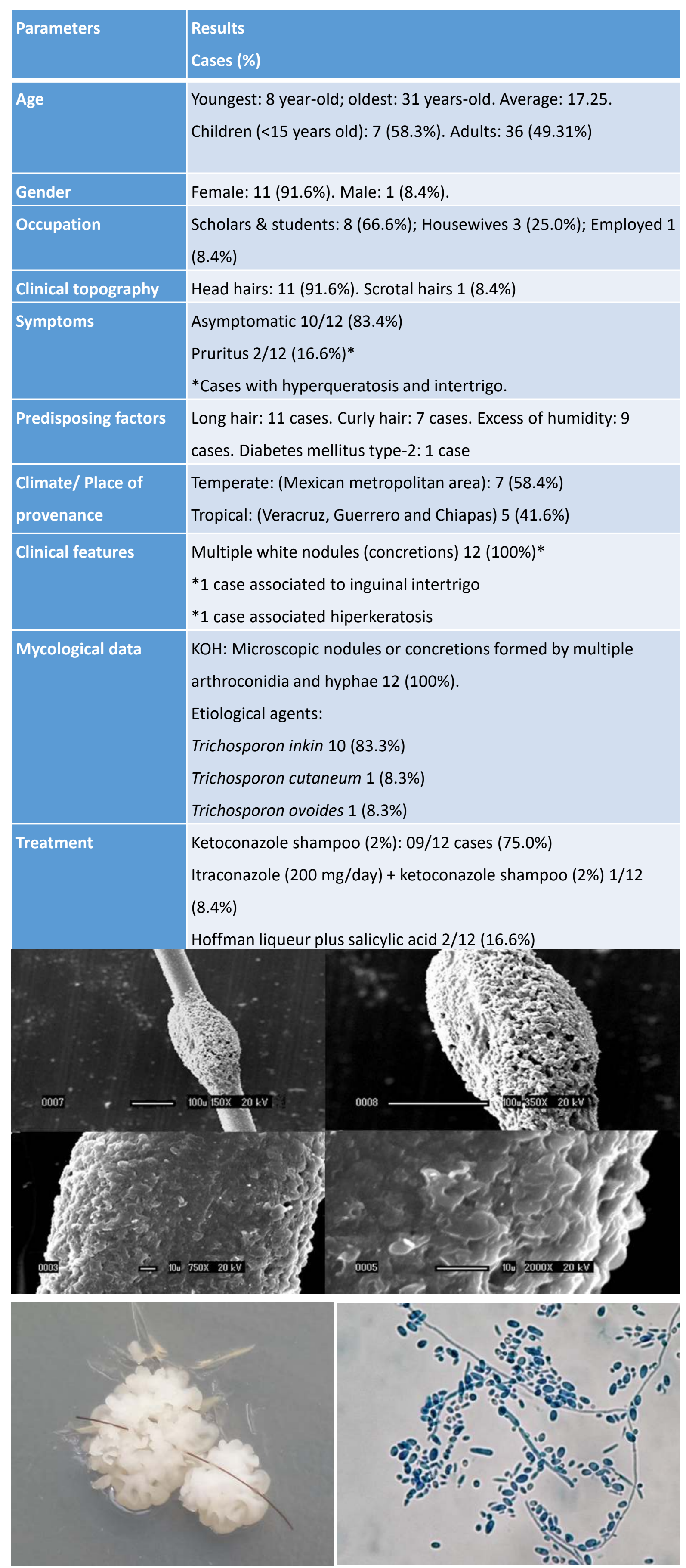

Table 2. Identification etiologic agents of white piedra and cutaneous lesions

\begin{tabular}{l|l|l|}
$\begin{array}{l}\text { Etiological agent } \\
\text { (Morphology) } \\
\text { Strains }\end{array}$ & $\begin{array}{l}\text { System VITEK } \\
\text { Strains }\end{array}$ & $\begin{array}{l}\text { 2YST ID-card } \\
\text { (Vitek-MS }\end{array}$ \\
\hline $\begin{array}{l}\text { Trichosporon } \text { ) } \\
\text { Strains } 12\end{array}$
\end{tabular}

*12 strains of white piedra and 2 of cutaneous lesions (nuchal hyperkeratosis and inguinal intertrigo) 